\title{
Post-prognostics decision-making strategy to manage the economic lifetime of a two-stack PEMFC system
}

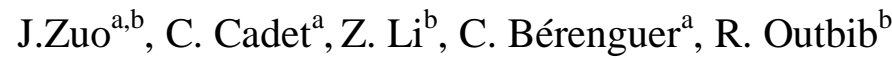 \\ ${ }^{a}$ Univ. Grenoble Alpes, CNRS, Grenoble INP1, GIPSA-lab, 38000 Grenoble, France \\ ${ }^{1}$ Institute of Engineering Univ. Grenoble Alpes \\ ${ }^{\mathrm{b}}$ LIS Laboratory, Aix-Marseille University, 13397 Marseille, France
}

Key Words: fuel cell stacks, durability, post-prognostics decision-making, decision criterion

\section{SUMMARY \& CONCLUSIONS}

The durability challenge of fuel cell technology is one of the main obstacles that hinder its wide commercialization. This work proposes a post-prognostics decision-making strategy to manage the economic lifetime of a two-stack PEMFC system. The influence of fuel cell deterioration and fuel consumption on fuel cell economic lifetime is studied. These two items are combined to construct the mixed decision criterion. Both the constant and dynamic type of system load demand are tested by the decision-making strategy. In simulation work, the hydrogen consumption/system-lifetime ratio and system lifetime are proposed as two evaluation criteria to assess the efficiency of the proposed decisionmaking strategy. Both the constant load and dynamic load simulation results show that when more weight is put on mitigating fuel cell deterioration, a bigger hydrogen consumption/system-lifetime ratio is achieved. For the system lifetime, an obvious increasing trend is observed when putting more weight on mitigating fuel cell deterioration. The proposed strategy can adequately handle the two items in the mixed criterion, generating the optimal load repartition for two-stack fuel cell systems. Therefore, a better economic lifetime can be achieved for the two stacks fuel cell system.

\section{INTRODUCTION}

Proton exchange membrane fuel cell (PEMFC) can achieve higher energy conversion efficiency and zero onboard emission compared to the traditional power unit. Therefore, it is well recognized as one of the most promising power units in industrial applications [1]. However, despite the promising application advantages, the PEMFC technology still suffers from limited durability and high application cost [2]. Durability is especially challenging. The US Department Of Energy (DOE) durability targets for stationary and transportation fuel cell applications are 40,000 and 5,000 hours respectively [3]. This target is hardly achieved in present fuel cell technology.

Several approaches have been proposed to deal with the durability challenge of PEMFC. Prognostics and Health
Management (PHM) [4-6] is one of the most effective methods that can help to extend the lifetime of PEMFC. PHM approach includes multiple application layers including data acquisition, data processing, diagnostic and prognostics. For the prognostics layer, model-based, data-driven and hybrid approaches are the three major types of developed methods. For model-based and hybrid prognostics, Jouin et al. [7] used a particle filtering $(\mathrm{PF})$ algorithm based on a polarization model, developed for this purpose. The more recently developed data-driven approaches do not rely directly on analytical deterioration model and they aim at taking benefit from the rapid growth in the dataset of fuel cell. For instance, Ma et al. [8] applied deep neural networks to form a prognostic model. However, the problem of how to use the results of the prognostic layer to further improve the fuel cell durability is rarely addressed in literature.

Energy management strategy (EMS) is a recently emerged approach for the decision-making process to improve fuel cell durability. K. Ettihir et al. [9] proposed an adaptive optimal power splitting EMS for PEMFC/battery hybrid system to improve its durability. More recently, several researchers have dealt with the prognostics related decisionmaking for multi-stack fuel cell systems. Yue et al. [10] brought forward a health-conscious EMS based on the prognostics-enable decision-making in the framework of PHM, thus linking management strategy and PHM. Herr et al. [11] proposed a decision process to manage the useful life of a multi-stacks fuel cell system. When considering the operation of fuel cell systems, fuel operation, besides the lifetime, should also be taken into consideration. Chen et al. [12] proposed the concept of economic lifetime. Fletcher et al. [13] put forward an EMS based on dynamic programming to minimize the fuel consumption and the system deterioration for a hybrid vehicle. From the above research works, two aspects need to be further developed: 1) it is necessary to integrate PHM into EMS as a crucial post-prognostics decision-making action, and 2) the system consumption should be considered together with the system durability performance.

In this work, a mixed criterion for post-prognostics 
decision-making is proposed for a two-stack fuel cell system. The objective of this work is to improve the system lifetime by considering the fuel cell deterioration as well as the fuel consumption. A Gamma process-based load dependent stochastic deterioration model is proposed to describe the deterioration of fuel cell stack. In the prognostic part, a conditional decision probability is calculated to collect the end of life (EoL) information of the system based on an analytical method. Then a fuel consumption rate function is introduced to calculate the system fuel consumption, combing the fuel consumption and the deterioration information, forming a mixed decision criterion. Finally, the decision-making phase outputs the optimal load repartition for the stacks according to the defined criterion.

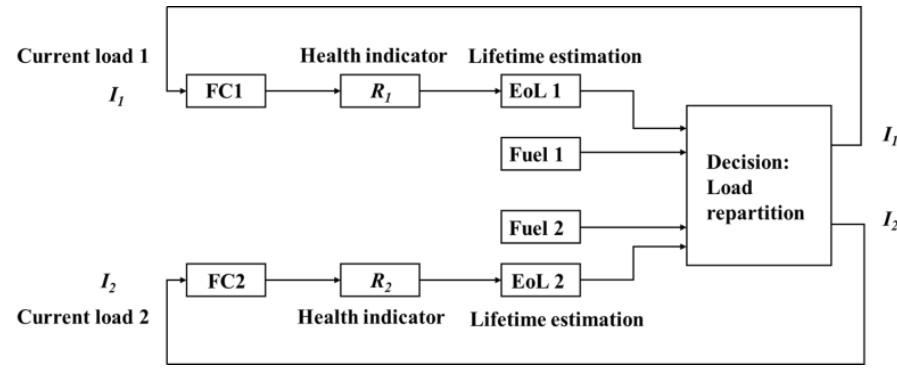

Fig. 1 Schematic of the post-prognostics decision-making strategy

\section{PROBLEM STATEMENT} the

The objective of the decision-making strategy is to find optimal load split for a two-stack fuel cell system during the operation period, in order to maximize the system service lifetime while taking into account the fuel consumption.

Presently, as the deterioration mechanism of PEMFC is not yet fully known, it is difficult to express the deterioration in a single formula. The research work developed by Jouin et al. [14]. shows that the deterioration of PEMFC can be directly related to the load applied to the system, using an empirical polarization equation [15]:

$$
V=n\left(\boldsymbol{E}_{\mathbf{0}}-\boldsymbol{R} I-\boldsymbol{A} \ln (I)-\boldsymbol{m}_{\mathbf{1}} \exp \left(\boldsymbol{m}_{\mathbf{2}} I\right)\right)
$$

the detailed physical meanings of parameters in equation (1) are summarized and listed in Table 1.

Table 1 Physical meaning of the parameters in equation (1)

\begin{tabular}{|c|c|}
\hline Parameters & Physical meaning \\
\cline { 1 - 2 } $\mathrm{n}$ & Number of cells in the stack \\
\hline$I$ & Operating current load \\
\hline$m_{1}$ & $\begin{array}{c}\text { Constant related to the mass } \\
\text { transport overpotential }\end{array}$ \\
\hline$m_{2}$ & $\begin{array}{c}\text { Voltage term related to the } \\
\text { reversible potential of PEMFC }\end{array}$ \\
\hline$E_{0}$ &
\end{tabular}

In equation (1), all fitting parameters that may vary with aging are written with bold letters. According to the research work of Bressel et al. [16], the overall resistance (R) increases as the stack ages, which indicates that the overall resistance can be used as a PEMFC health indicator.

The hydrogen consumption rate of one PEMFC stack is denoted as $c_{\mathrm{H} 2}(t)$, which is defined as a function of the current load $I(t)$. The global hydrogen consumption of a PEMFC stack during time period $t_{0}$ is calculated by:

$$
C_{H 2}=\int_{0}^{t_{0}} c_{H 2}(I) d t
$$

The proposed post-prognostic decision-making strategy is developed to make a trade-off between the PEMFC deterioration and the fuel consumption. Therefore, two separate but complementary objectives to be minimized are defined:

1. PEMFC deterioration level in order to extend the system lifetime as long as possible.

2. Hydrogen consumption to lower the operation cost while satisfying the operation of the system demand.

These criteria are contradictory. Decreasing the deterioration will lead to keep the current in an intermediate, whereas minimizing $\mathrm{H}_{2}$ consumption will lead to minimize the current. Thus, a suitable current for each fuel cell stack has to be defined by the post-prognostic decision.

The general problem schematic is shown in Fig. 1. Firstly, the two-stack fuel cell system is operating for a certain period. Then, lifetime and consumed hydrogen fuel are calculated for both fuel cells. At last, the decision block is used to integrate the input information from previous blocks, and outputs the optimal load repartition for the two fuel cell stacks. The following assumptions are made on the two- stacks fuel cell system:

1. Two fuel cell stacks are connected in parallel

2. The two fuel cell stacks in the networking system are identical. The output power of each stack ranges from the minimal output power $P_{\min }$ to maximum output power $P_{\max }$.

3. The value of fuel cell overall resistance $(R)$ is considered to be measured in this work. The resistance values can be further estimated thanks to an observer.

\section{POST-PROGNOSTICS DECISION-MAKING}

This section focuses on the methodology of the proposed post-prognostics decision-making strategy. More details on the load-dependent deterioration modeling and the associated decision probability are presented in [17].

\subsection{Gamma process deterioration modeling}

From equation (1), the overall resistance of PEMFC stack is chosen as the health indicator and is further modeled by a Gamma process to study system deterioration [14, 18, 19]. The overall resistance is assumed to be measurable in realtime. A Gamma process is a stochastic process with independent, positive increments that obeys a Gamma distribution $\Gamma(\alpha, \beta)$. There are two key parameters in a standard Gamma process, the shape parameter $\alpha$ and scale parameter $\beta$. Thanks to the stochastic characteristics, various deterioration behaviors can be simulated by using different $\alpha$ 
and $\beta$ values. When given the $\alpha$ and $\beta$ values, the deterioration rate $\mathrm{r}$ is calculated by:

$$
r=\alpha \cdot \beta
$$

In this work, the deterioration level of the indicator $R$ is modeled by a Gamma process. The scale parameter $\beta$ is defined as a constant in this work. The shape parameter $\alpha$ is further modeled as a function of the demand load $I$, i.e. the deterioration rate is also a load-dependent function $r(I)$.

\subsection{PEMFC load-dependent deterioration and fuel consumption modeling}

To describe the deterioration rate function $r(I)$, the parabola function shown in Fig. 2 is used. This is developed based on the deterioration characteristics of PEMFC [17]. As shown in Fig. 2, from minimal operation load $I_{\text {min }}$ to nominal load $I_{\text {nom }}$ and maximum load $I_{\max }$, the corresponding average deterioration rate follows an order of $\bar{r}_{1}>\bar{r}_{3}>\bar{r}_{2}$.

Furthermore, according to Dépature C. et al. [20], the hydrogen fuel consumption rate can be described as a linear function. However, in practical applications, when considering the global stack system, the energy consumption auxiliary components including the air compressor, the cooling pump, and the electronic control device should also be taken into consideration with electrical energy consumption [12]. This work introduced a quadratic equation to describe the global system fuel consumption considering the characteristics of fuel cell auxiliary components, as shown in Fig. 2.

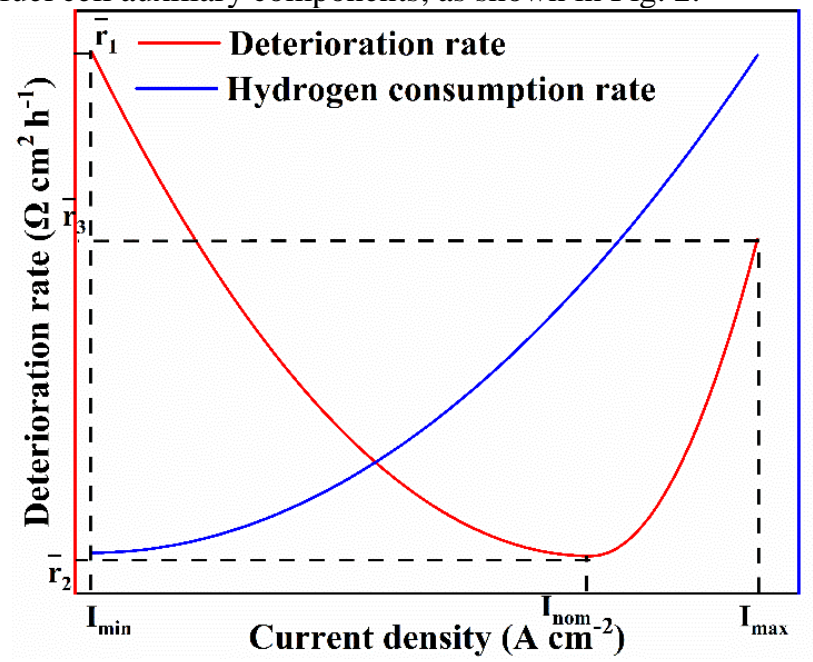

Fig. 2 Deterioration and hydrogen consumption rates

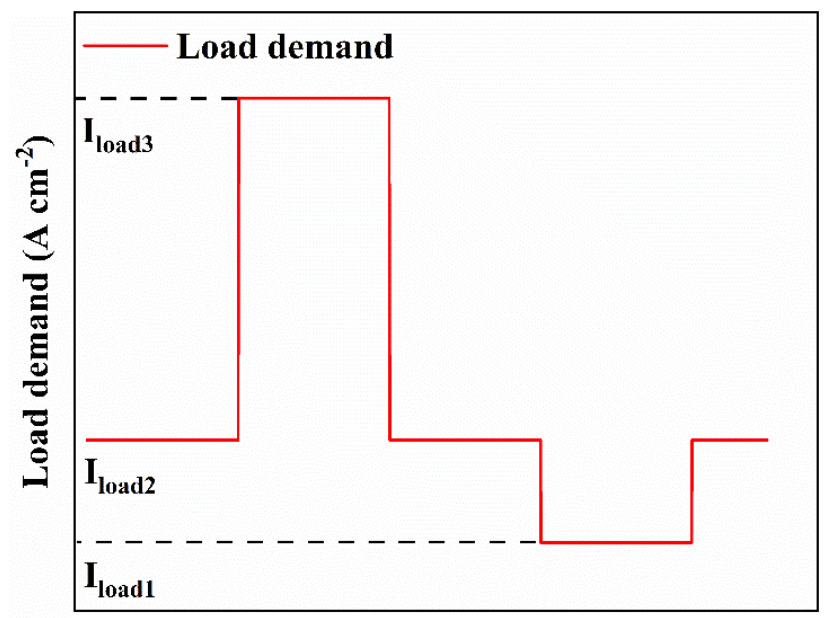

Time (h)

Fig. 3 Dynamic system load demand

\subsection{Mixed criterion for a two-stack PEMFC system}

A multi-step decision-making strategy is designed for the decision-making phase. The same decision criterion is applied to each decision step at each decision time $k * \tau$, where $k$ is the decision step, and $\tau$ is the time length of a single decision step.

At each decision time, the deterioration level (i.e. the value of $R$ ) is monitored and based on this measured level $R_{\text {obs }}$, a conditional probability to reach a deterioration level threshold $F T_{d}$ at the end of the next period is computed for the different possible load repartitions. The calculation approach used here is an exhaustive search. The load repartition decision is eventually made by considering a criterion including the conditional failure probabilities for each stack. The conditional decision probability $P_{d}$ at decision step $k$ $\left(P_{d}^{(k)}\right)$ is calculated using the following equation:

$$
\begin{aligned}
P_{d}^{(k)}=P\left(T_{F T_{d}^{(k)}} \leq k \tau\right) & =P\left(R(k \tau)>F T_{d}^{(k)}\right) \\
& =\frac{\Gamma\left(\alpha t,\left(F T^{(k)} d^{\left.\left.-R^{(k-1)}{ }_{o b s}\right) \cdot \beta\right)}\right.\right.}{\Gamma(\alpha t)}
\end{aligned}
$$

where $F T_{d}^{(k)}$ is the decision threshold at decision step $k$. $\mathrm{R}(k \tau)$ is the simulated deterioration level at decision step $k$. $R^{(k-1)}$ obs represents the measured deterioration level at step $(k-1)$.

The consumption of the system under the different possible repartition is also evaluated for each of the stacks. The mixed criterion is constructed to consider both deterioration and fuel consumption, and is formulated as follows:

$$
\begin{array}{r}
\text { Criterion }=\max \left\{w \cdot \operatorname{Norm}\left\{\left(1-P_{d 1}\right) \cdot\left(1-P_{d 2}\right)\right\}+\right. \\
\left.(1-w) \cdot \operatorname{Norm}\left\{1 /\left(\text { Fuel }_{1}+\text { Fuel }_{2}\right)\right\}\right\}
\end{array}
$$

where $w$ is the weight between fuel cell stack deterioration and system fuel consumption. Norm represents the normalization calculation to make sure that the two items in equation (5) have the same order of magnitude. $P_{d 1}$ and $P_{d 2}$ represent the conditional failure probability of fuel cell stack 1 and stack 2. Fuel 1 and Fuel $_{2}$ represents the total fuel consumption of two PEMFC stacks. 


\subsection{Decision-making process}

The decision is eventually made based on the joint criterion and the load repartition decision is determined as the one that maximizes the joint criterion defined in equation (5). A trade-off between the fuel cell deterioration and system fuel consumption is achieved by assigning different weights, $w$.

At each decision step $k$, an exhaustive search approach is used in search of the optimal load repartition. Whenever the system failure probability and global system hydrogen consumption is evaluated based on the Gamma process simulation, the maximum value of the mixed criterion defined as equation (5) is applied to choose the optimal load repartition for each stack. The available control variable is decided as follows: for a given system load demand $I_{\text {load }}$, and $I_{1}$ for $\mathrm{FC} 1$ (ranges from $I_{\min }$ to $I_{\max }$ with a fixed increment step), the operation load for FC2 is decided by the following:

$$
\left\{\begin{array}{c}
I_{\text {load }}-I_{1} \leq I_{2} \\
I_{\min } \leq I_{2} \leq I_{\max }
\end{array}\right.
$$

Both constant and dynamic system load demands are studied. For constant system load demand, $I_{\text {load }}$ is defined as $I_{\text {load } 2}$ during the whole operation period as shown in Fig. 3. And the dynamic system demand is shown in Fig. 3 and its value varies among $I_{\text {load } 1}, I_{\text {load } 2}$ and $I_{\text {load } 3}$.

\subsection{Performance evaluation}

To estimate the performance of the proposed decisionmaking strategy, a performance estimation index is the system lifetime.

Another performance estimation index is the system level hydrogen consumption rate defined by the following equation is chosen as the first estimate index:

$$
\mathrm{H}_{2} \text { consumption/System - lifetime }
$$

where the $\mathrm{H}_{2}$ consumption represents the total hydrogen consumption during the service period, and system lifetime equals to EoL. The calculation method of the system lifetime is the same as introduced in [17].

The corresponding results of these two indexes are summarized and discussed in the following.

\section{RESULTS AND DISCUSSION}

\subsection{Basic value settings}

The initial resistance value $R_{0}$ is set as $0.1798 \Omega \mathrm{cm}^{2}$. The values of $I_{\text {min }}, I_{\text {nom }}$ and $I_{\text {max }}$ are set as 2,8 , and $10 \mathrm{Acm}^{-2}$ for each fuel cell stack. The deterioration rate values in Fig. 3 are calculated using the same method introduced in [17]. A failure threshold $(F T)$ is defined for PEMFC stack to calculate the EoL value and the $F T$ is chosen as 3 . Three key values of the dynamic load demand shown in Fig. 3 are set as 12.4, 13, and $15 \mathrm{~A} \mathrm{~cm}^{-2}$, for $I_{\text {load } 1}, I_{\text {load } 2}$ and $I_{\text {load } 3}$ respectively. The constant load demand in this work is set as $13 \mathrm{~A} \mathrm{~cm}^{-2}$. The scale parameter of Gamma process $\beta$ equals to 0.36 . For the Gamma process simulation, the total simulation length is 2700 hours. The single decision step time length $\tau$ is 150 hours.

\subsection{Post-prognostics decision-making results}

To study the influence of different weights of the criteria as introduced in equation (5), 100 simulations runs were performed, and four different $w$ values were used. Each simulation is compared with the results developed under constant load $\left(I_{1}=I_{2}=I_{\text {load }} / 2\right)$. For constant system load demand simulations, the results on the overall system level hydrogen consumption rate/System-lifetime ratio are shown in Fig. 4. Globally, the hydrogen consumption rate/systemlifetime ratio decreases with $w$ value. By contrast, the results without decision show rough variations between the different simulation times. This phenomenon shows that the proposed decision-making strategy can decrease the failure risk of the system, achieving a steadier operation.

Table 2 further summarizes the hydrogen consumption rate results. The results of the comparison experiment have the lowest rate value, $40.88 \mathrm{gs}^{-1}$. And the hydrogen consumptions rate results for $w=0.3, w=0.5, w=0.7$, and $w=0.9$ are $41.04,41.5,47.67$, and $58.16 \mathrm{~g} \mathrm{~s}^{-1}$ respectively. This result is logical. The higher value of $w$ means that, based on equation (6), the trade-off rules tend to make a decision that consumes more fuel to mitigate the deterioration. Otherwise, decreasing the weights $w$ means that less fuel consumption is appreciated. During the operation, the decision strategy tends to increase the fuel consumption but the lifetime can be considerably improved.

For the system lifetime distribution histograms are plotted in Fig. 5 and Fig. 6. Fig. 5 a) shows the system lifetime results developed without a decision-making strategy. $68 \%$ of the system lifetime in Fig. 5 are distributed between 1200 and 1800 hours. Whereas, when applying the proposed decisionmaking strategy, the system lifetime is shifting to a bigger distribution interval. $65 \%$ percent of the system lifetime is distributed between 1400 and 2800 hours for $w=0.3$. For $w=0.7$ and 0.9 , the system lifetime distributed between 1400 and 2800 hours is $86 \%$ and $97 \%$ respectively. The median and mean system lifetime statistic values shown in Table 2 also prove that the system can achieve a longer lifetime by using bigger $w$. Therefore, in order to achieve a maximum economic lifetime for fuel cell systems, the practitioners can choose a proper $w$ for the mixed criterion, then apply the decisionmaking strategy to deal with the trade-off between the fuel cell stack deterioration and system fuel consumption, achieving the desired economic lifetime.

For the simulation results derived from dynamic system load demand simulation, the general conclusion is similar to the constant load demand. From Table 2, the hydrogen consumption value is slightly larger than with constant load demand. The value for $w=0.7$ and $w=0.9$ are 52.38 and $58.62 \mathrm{~g} \mathrm{~s}^{-1}$ respectively, much greater than the value for $w=0.3$ and 0.5 . The system lifetime distribution is exhibited in Fig. 7. Compared with the results in Fig. 5 b), $81 \%$ of the system lifetime is distributed between 1400 and 2800 hours for $w=0.3$. And for $w=0.5, w=0.7$, and $w=0.9$, the lifetime distributed between 1400 and 2800 hours is $89 \%$, $93 \%$, and

$98 \%$ respectively. Therefore, for the dynamic load demand, the proposed decision-making strategy still works well. The median and mean system lifetime statistic results in Table 2 
give the same conclusions.

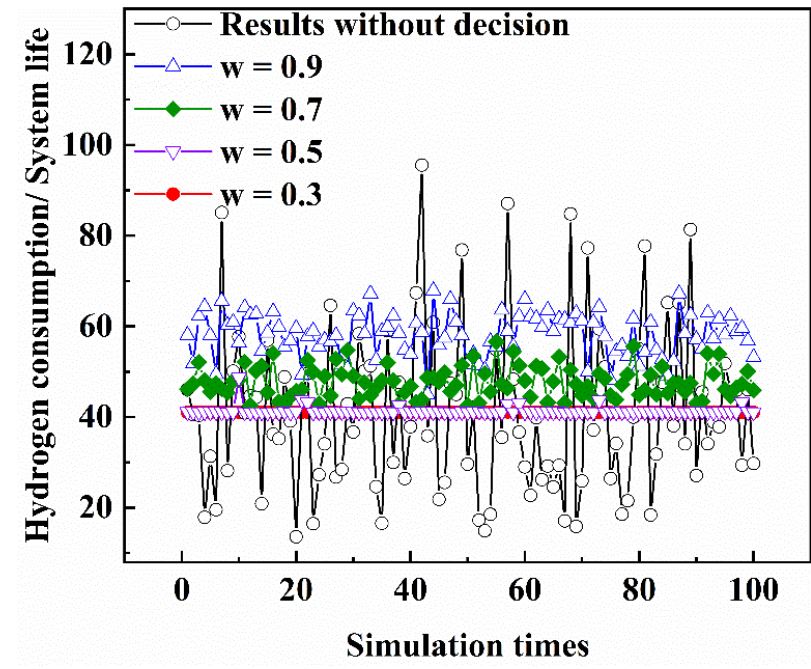

Fig. 4 Hydrogen consumption/System-lifetime ratio (constant load demand).
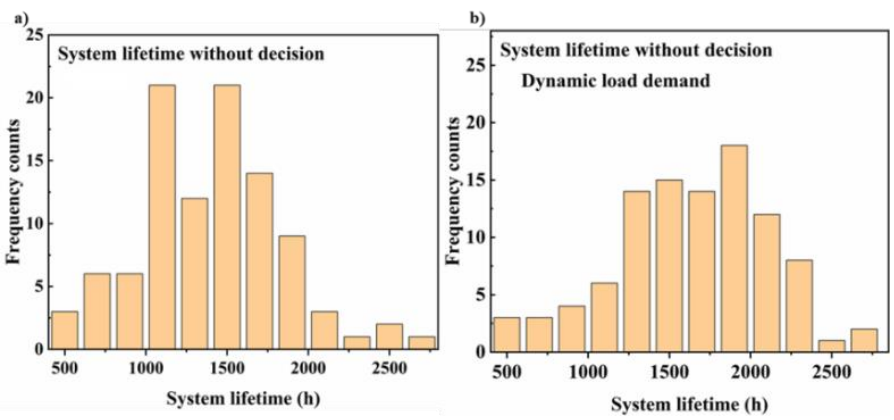

Fig. 5 System lifetime distribution histogram - without decision-making strategy. a) constant load demand, b) dynamic load demand.
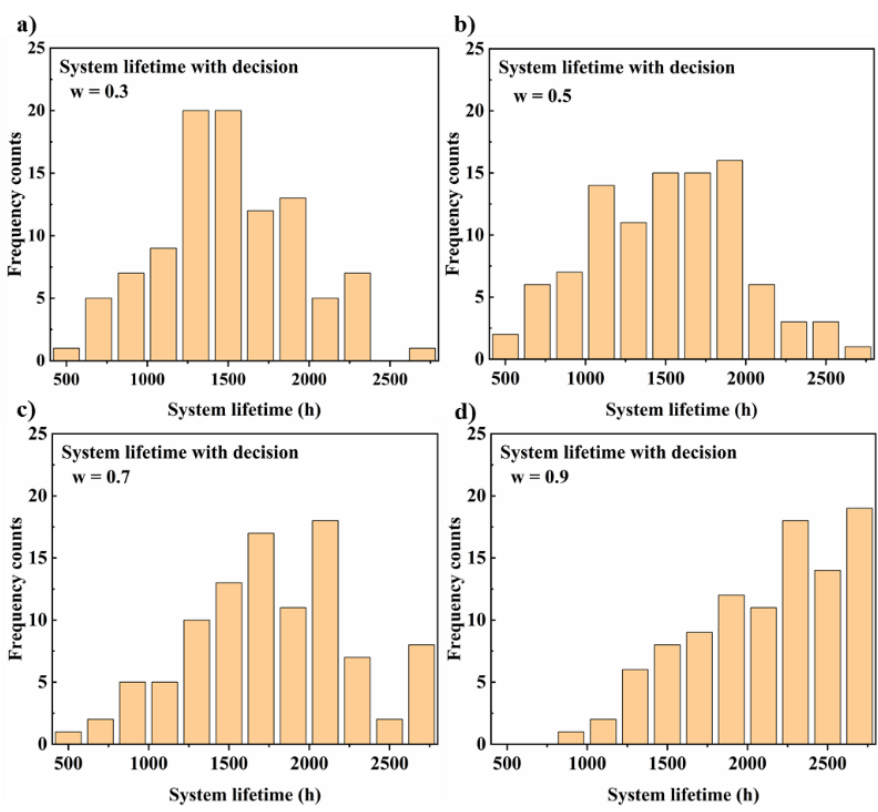

Fig. 6 System lifetime distribution histogram - Constant load demand. a) $w=0.3, b) w=0.5, c) w=0.7, d) w=0.9$.
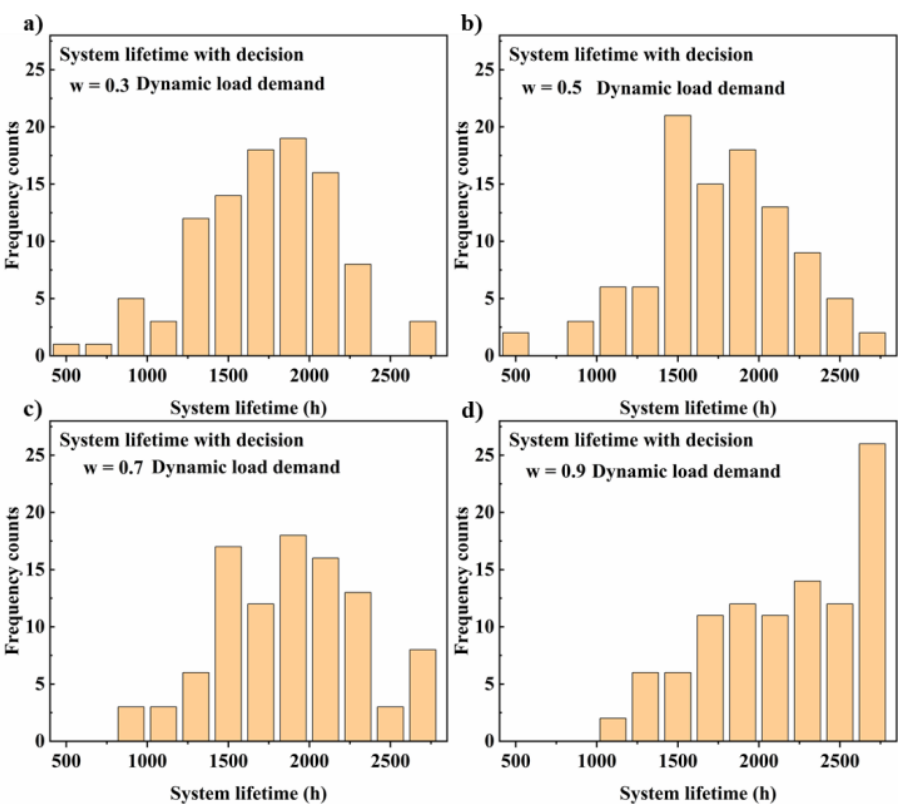

Fig. 7 System lifetime distribution histogram - Dynamic load demand. a) $w=0.3, b) w=0.5, c) w=0.7, d$ ) $w=0.9$.

\section{CONCLUSIONS}

A load-dependent deterioration model is developed to model the deterioration of a multi-stack fuel cell system. To manage its economic system life, a joint decision-making criterion which includes both fuel cell deterioration and fuel cell consumption is proposed to formulate the post-prognostics decision-making strategy. For the constant type system load demand, a larger hydrogen consumption / system-lifetime ratio $(w)$ is achieved when applies more weights on mitigating fuel cell deterioration. $68 \%$ of the system life developed without decision-making strategy is distributed between 1200 and 1800 hours. When applying the decision-making strategy, the system's life is improved. For $w=0.7$ and 0.9 , the percent of system life distributed between 1400 and 2800 hours reach to $86 \%$ and $97 \%$. The dynamic system load demand simulation results prove the same trend. The percent of system life distributed between 1400 and 2800 hours for $w=0.3,0.5$, 0.7 , and 0.9 are $81 \%, 89 \%, 93$, and $98 \%$ respectively. The proposed decision-making strategy can help to make a compromise between the fuel cell system deterioration and system fuel consumption, and thus greatly improve the system life.

Table 2 System hydrogen consumption and system life results

\begin{tabular}{|c|c|c|c|}
\hline & $\begin{array}{c}\text { Mean } \\
\text { hydrogen } \\
\text { consumption } \\
\text { rate }\left(\mathrm{g} \mathrm{s}^{-1}\right)\end{array}$ & $\begin{array}{c}\text { Median } \\
\text { system life } \\
(\mathrm{h})\end{array}$ & $\begin{array}{c}\text { Mean } \\
\text { system life } \\
(\mathrm{h})\end{array}$ \\
\hline $\begin{array}{c}\text { Without } \\
\text { decision- } \\
\text { making }\end{array}$ & 40.88 & 1411.5 & 1387.9 \\
\hline $\begin{array}{c}\text { W }=0.3 \\
\text { Constant } \\
\text { load }\end{array}$ & 41.04 & 1540.5 & 1524.2 \\
\hline
\end{tabular}




\begin{tabular}{|c|c|c|c|}
\hline $\begin{array}{c}\mathrm{W}=0.5 \\
\text { Constant } \\
\text { load }\end{array}$ & 41.5 & 1525.5 & 1502.5 \\
\hline $\begin{array}{c}\mathrm{W}=0.7 \\
\text { Constant } \\
\text { load }\end{array}$ & 47.67 & 1760 & 1750.4 \\
\hline $\begin{array}{c}\mathrm{W}=0.9 \\
\text { Constant } \\
\text { load }\end{array}$ & 58.16 & 2201 & 2115.8 \\
\hline $\begin{array}{c}\mathrm{W}=0.3 \\
\text { Dynamic } \\
\text { load }\end{array}$ & 47.55 & 1763.5 & 1726.3 \\
\hline $\begin{array}{c}\mathrm{W}=0.5 \\
\text { Dynamic } \\
\text { load }\end{array}$ & 47.78 & 1776 & 1748.5 \\
\hline $\begin{array}{c}\mathrm{W}=0.7 \\
\text { Dynamic } \\
\text { load }\end{array}$ & 52.38 & 1870.5 & 1867.6 \\
\hline $\begin{array}{c}\mathrm{W}=0.9 \\
\text { Dynamic } \\
\text { load }\end{array}$ & 58.62 & 2247 & 2159.4 \\
\hline
\end{tabular}

\section{REFERENCES}

1. C. Zheng, G. Xu, Y. Park, W. Lim and S. Cha, "Prolonging fuel cell stack lifetime based on pontryagin's minimum principle in fuel cell hybrid vehicles and its economic influence evaluation", Journal of Power Sources, vol.248, pp. 533-544 2014.

2. J. Zhao and X. Li, "A review of polymer electrolyte membrane fuel cell durability for vehicular applications: Degradation modes and experimental techniques", Energy Conversion and Management, vol.199, pp. 1120222019.

3. N. Garland, T. Benjamin and J. Kopasz, "Doe fuel cell program: Durability technical targets and testing protocols", ECS Transactions, vol.11, no.1, pp. 923-931, 2019/12/19 2019.

4. M. Jouin, R. Gouriveau, D. Hissel, M.-C. Péra and N. Zerhouni, "Phm of proton-exchange membrane fuel cellsa review", 2013.

5. D. Zhang, C. Cadet, N. Yousfi- Steiner, F. Druart and C. Bérenguer, "Phm- oriented degradation indicators for batteries and fuel cells", Fuel Cells, vol.17, no.2, pp. 2682762017.

6. E. Lechartier, E. Laffly, M.-C. Péra, R. Gouriveau, D. Hissel and N. Zerhouni, "Proton exchange membrane fuel cell behavioral model suitable for prognostics", International Journal of Hydrogen Energy, vol.40, no.26, pp. 8384-8397 2015.

7. M. Jouin, R. Gouriveau, D. Hissel, M.-C. Péra and N. Zerhouni, "Prognostics of proton exchange membrane fuel cell stack in a particle filtering framework including characterization disturbances and voltage recovery", in 2014 International Conference on Prognostics and Health Management, pp. 1-6, IEEE, 2014.

8. R. Ma, T. Yang, E. Breaz, Z. Li, P. Briois and F. Gao,
"Data-driven proton exchange membrane fuel cell degradation predication through deep learning method", Applied Energy, vol.231, pp. 102-115, 2018/12/01/ 2018.

9. K. Ettihir, L. Boulon and K. Agbossou, "Optimizationbased energy management strategy for a fuel cell/battery hybrid power system", Applied Energy, vol.163, pp. 1421532016.

10. M. Yue, S. Jemei and N. Zerhouni, "Health-conscious energy management for fuel cell hybrid electric vehicles based on prognostics-enabled decision-making", IEEE Transactions on Vehicular Technology, vol.68, no.12, pp. 11483-114912019.

11. N. Herr, J.-M. Nicod, C. Varnier, L. Jardin, A. Sorrentino, D. Hissel and M.-C. Péra, "Decision process to manage useful life of multi-stacks fuel cell systems under service constraint", Renewable energy, vol.105, pp. 590-600 2017.

12. H. Chen, P. Pei and M. Song, "Lifetime prediction and the economic lifetime of proton exchange membrane fuel cells", Applied Energy, vol.142, pp. 154-163, 2015/03/15/ 2015.

13. T. Fletcher, R. Thring and M. Watkinson, "An energy management strategy to concurrently optimise fuel consumption \& pem fuel cell lifetime in a hybrid vehicle", international journal of hydrogen energy, vol.41, no.46, pp. 21503-21515 2016.

14. M. Jouin, R. Gouriveau, D. Hissel, M.-C. Péra and N. Zerhouni, "Degradations analysis and aging modeling for health assessment and prognostics of pemfc", Reliability Engineering \& System Safety, vol.148, pp. 78-95 2016.

15. J. Kim, S. M. Lee, S. Srinivasan and C. E. Chamberlin, "Modeling of proton exchange membrane fuel cell performance with an empirical equation", Journal of the electrochemical society, vol.142, no.8, pp. 26701995.

16. M. Bressel, M. Hilairet, D. Hissel and B. O. Bouamama, "Remaining useful life prediction and uncertainty quantification of proton exchange membrane fuel cell under variable load", IEEE Transactions on Industrial Electronics, vol.63, no.4, pp. 2569-2577 2016.

17. J. Zuo, C. Cadet, Z. Li, C. Berenguer and R. Outbib, "Post-prognostics decision making for a two-stacks fuel cell system based on a load-dependent deterioration model", in PHM Society European Conference, pp. 9-9, 2020.

18. D. Zhang, C. Cadet, N. Yousfi-Steiner and C. Bérenguer, "Proton exchange membrane fuel cell remaining useful life prognostics considering degradation recovery phenomena", Proceedings of the Institution of Mechanical Engineers, Part O: Journal of Risk and Reliability, vol.232, no.4, pp. 415-424 2018.

19. D. Zhang, P. Baraldi, C. Cadet, N. Yousfi-Steiner, C. Bérenguer and E. Zio, "An ensemble of models for integrating dependent sources of information for the prognosis of the remaining useful life of proton exchange membrane fuel cells", Mechanical Systems and Signal Processing, vol.124, pp. 479-501 2019.

20. C. Dépature, S. Jemei, L. Boulon, A. Bouscayrol, N. 
Marx, S. Morando and A. Castaings, "Ieee vts motor vehicles challenge 2017-energy management of a fuel cell/battery vehicle", in 2016 IEEE Vehicle Power and Propulsion Conference (VPPC), pp. 1-6, IEEE, 2016.

\section{BIOGRAPHIES}

Jian Zuo, PhD student

Gipsa-Lab

Univ. Grenoble Alpes

11, Rue des Mathematiques

Grenoble 38402 Saint Martin d'Heres, France

e-mail: jian.zuo@grenoble-inp.fr

Jian is currently a PhD student at Gipsa-Lab, Univ. Grenoble

Alpes. His research interests concern Prognostics and health management (PHM) of Fuel cell system.

Catherine Cadet, $\mathrm{PhD}$, Assistant professor

Gipsa-Lab

Univ. Grenoble Alpes

11, Rue des Mathematiques

Grenoble 38402 Saint Martin d'Heres, France

e-mail: catherine.cadet@ grenoble-inp.fr

Catherine Cadet is an assistant professor in automatic control and process engineering at Univ. Grenoble Alpes, CNRS, Grenoble INP - Gipsa-lab (Grenoble, France). Her present research interests concern Prognosis and Health Monitoring (PHM) approaches for Fuel Cells, and more specially diagnosis and prognosis aspects, and additionally Model Predictive Control and sliding mode observers for environmental and energetical processes.

Zhongliang $\mathrm{Li}, \mathrm{PhD}$, Associated professor

LIS Lab (UMR CNRS 7072)

Aix-Marseille University

Fac. St Jérôme, Avenue Escadrille Normandie-Niemen

Marseille 13397, France.

e-mail: zhongliang.li@lis-lab.fr

Zhongliang Li received the B.S. and M.S. degrees in electrical engineering from Tsinghua University, Beijing, China, in 2009 and 2011 respectively. He received Ph.D. degree in automation from Aix-Marseille University 2014.

From 2014 to 2016, he was a Post-Doctoral Research Associate with labs FEMTO-ST (UMR CNRS 6174) and FCLAB (CNRS 3539), Belfort, France. From 2016, he is an associate professor of Aix-Marseille University with lab LIS (UMR CNRS 7020). His research interests include modeling, control, diagnosis and prognosis with applications to fuel cell systems, electric vehicles, and other energy systems.

Christophe Bérenguer, $\mathrm{PhD}$, Professor

Gipsa-Lab

Univ. Grenoble Alpes

11, Rue des Mathematiques

Grenoble 38402 Saint Martin d'Heres France

e-mail: christophe.berenguer@grenoble-inp.fr

Christophe Bérenguer is a professor of reliability and maintenance engineering, systems monitoring \& control systems at Univ. Grenoble Alpes, CNRS, Grenoble INP Gipsa-lab (Grenoble, France). From 1997 to 2011, he was professor at Troyes University of Technology (Troyes,
France). He serves as an Associate Editor for the Journal of Risk and Reliability. His research interests include system health monitoring, RUL prognosis and control, stochastic modeling of systems deterioration, performance evaluation and optimization of dynamic maintenance policies, and probabilistic safety assessment.

Rachid Outbib, PhD, Professor

LIS Lab (UMR CNRS 7072)

Aix-Marseille University

Fac. St Jérôme, Avenue Escadrille Normandie-Niemen

Marseille 13397, France.

e-mail: Rachid.Outbib@ lis-lab.fr

Rachid Outbib has received his $\mathrm{Ph}$. degree in applied mathematics in 1994 and his HDR in automatics control in 1998, both from the university of Metz (France) and the university of Amiens (France). From 2003 to 2006 he was full professor at the university of technology at Belfort (France). Since 2007 he is full professor at university Aix-Marseille (France). His main research interests concern nonlinear systems methods with applications energetic systems. 